\title{
Delivery of bone morphogenetic protein-2 and substance $P$ using graphene oxide for bone regeneration
}

This article was published in the following Dove Press journal:

International Journal of Nanomedicine

7 May 2014

Number of times this article has been viewed

\author{
Wan-Geun La' \\ Min Jin' \\ Saibom Park ${ }^{1,2}$ \\ Hee-Hun Yoon' \\ Gun-Jae Jeong' \\ Suk Ho Bhang' \\ Hoyoung Park ${ }^{1,2}$ \\ Kookheon Char ${ }^{1,2}$ \\ Byung-Soo Kim ${ }^{1,3}$ \\ 'School of Chemical and Biological \\ Engineering, Seoul National University, \\ Seoul, Republic of Korea; ${ }^{2}$ The \\ National Creative Research Initiative \\ Center for Intelligent Hybrids, Seoul \\ National University, Seoul, Republic \\ of Korea; 'Institute of Bioengineering, \\ Institute of Chemical Processes, \\ Engineering Research Institute, Seoul \\ National University, Seoul, Republic \\ of Korea
}

Correspondence: Byung-Soo Kim School of Chemical and Biological Engineering, Seoul National University, 599 Gwanak-ro, Gwanak-gu, Seoul I5I-744, Republic of Korea Tel $+822880 \quad 1509$

Fax +82 28881604

Email byungskim@snu.ac.kr

Kookheon Char

School of Chemical and Biological

Engineering, Seoul National University,

599 Gwanak-ro, Gwanak-gu,

Seoul I5I-744, Republic of Korea

Tel +82 2880743 I

Fax +82 28737523

Email khchar@plaza.snu.ac.kr
Abstract: In this study, we demonstrate that graphene oxide (GO) can be used for the delivery of bone morphogenetic protein-2 (BMP-2) and substance $\mathrm{P}$ (SP), and that this delivery promotes bone formation on titanium (Ti) implants that are coated with GO. GO coating on Ti substrate enabled a sustained release of BMP-2. BMP-2 delivery using GO-coated Ti exhibited a higher alkaline phosphatase activity in bone-forming cells in vitro compared with bare Ti. SP, which is known to recruit mesenchymal stem cells (MSCs), was co-delivered using Ti or GO-coated Ti to further promote bone formation. SP induced the migration of MSCs in vitro. The dual delivery of BMP-2 and SP using GO-coated Ti showed the greatest new bone formation on Ti implanted in the mouse calvaria compared with other groups. This approach may be useful to improve osteointegration of $\mathrm{Ti}$ in dental or orthopedic implants.

Keywords: bone morphogenetic protein-2, bone regeneration, graphene oxides, stem cell recruitment, substance $\mathrm{P}$

\section{Introduction}

Bone morphogenetic proteins (BMPs) are the most potent osteoinductive protein for bone regeneration. Among BMPs, BMP-2 is a well-known growth factor for inducing osteogenic differentiation of stem cells and has been used clinically for bone regeneration. ${ }^{1-6}$ Despite the great osteoinductivity of BMP-2, several factors limit the clinical use of BMP-2: clinical treatment requires a large dose of BMP-2, which could potentially lead to several side effects such as over bone growth, inflammation, and uncontrolled bone formation, and loaded BMP-2 could rapidly diffuse from protein carriers. $^{6-8}$ To overcome these limitations, an appropriate delivery platform that enables local delivery of BMP-2 to the sites of interest and sustained release from the carrier should be developed. ${ }^{6,9-11}$

The osteoregeneration process depends not only on the osteoinductive BMP-2 and the protein carrier but also on osteoregenerative cells such as mesenchymal stem cells (MSCs) or osteoprogenitor cells. ${ }^{2}$ To improve bone regeneration at defect sites, it would be useful to recruit stem cells to the defect areas. ${ }^{12,13}$ Substance P (SP) is a highly conserved 11 amino acid neuropeptide that mediates pain perception. ${ }^{14}$ It has been reported that SP is involved in many processes, such as the regulation of inflammation, wound healing, and angiogenesis. ${ }^{15-19}$ Recently, it was demonstrated that SP promotes recruitment and mobilization of MSCs to blood circulation. ${ }^{20} \mathrm{SP}$ has been reported to be effective in tissue regeneration by promoting recruitment of MSCs to damaged tissues, making it an ideal candidate for promoting endogenous stem cell mobilization. ${ }^{18,20,21}$ 
Local delivery to a defect site and sustained release of protein growth factors are important for bioimplants. Titanium (Ti) has been widely used for dental implants because of its biocompatibility and good mechanical properties..$^{22-25}$ However, Ti does not integrate well with bone tissue. ${ }^{22}$ To improve the osteointegration of Ti implants, numerous studies have proposed Ti implants coated with various inorganic materials, such as hydroxyl apatite or calcium phosphate, to enhance regeneration efficacy. ${ }^{22-25}$ Another approach to improve the osteointegration of $\mathrm{Ti}$ implants could be to use BMP-2 instead of inorganic materials. BMP-2 induces osteogenic differentiation of stem cells, which can enhance the osteointegration of implants by forming bone at the space between the implants and the implantation site. ${ }^{26,27}$

In a previous study, we used graphene oxide (GO)coated Ti implants as a vehicle to deliver BMP-2 for bone regeneration. ${ }^{28}$ The ionized groups of GO enable protein delivery by binding through electrostatic interaction. ${ }^{28-30} \mathrm{In}$ addition, GOs' hydrophobic domains can interact with those of proteins' by hydrophobic $\pi-\pi$ stacking. ${ }^{31-33}$ Therefore, GO can allow for a sustained release of loaded protein, which is critical for clinical use of protein delivery. In this study, we delivered both BMP-2 and SP using GO-coated Ti to further promote bone formation compared with BMP-2 delivery using GO-coated Ti. SP may promote $\mathrm{MSC}$ recruitment ${ }^{20}$ to the implants, possibly resulting in osteogenic differentiation by BMP-2 and subsequent bone formation.

\section{Materials and methods Preparation of GO}

Graphite oxide was prepared from graphite using the modified Hummer's method. ${ }^{29}$ Prepared GO was exfoliated onto each $\mathrm{GO}^{-\mathrm{COO}^{-}}$sheet by ultrasonification in an ice bath. The resultant brown dispersion was centrifuged at 3,470 $\mathrm{g}$ for 5 minutes to remove any unexfoliated powder. Positively charged graphene oxide $\left(\mathrm{GO}-\mathrm{NH}_{3}{ }^{+}\right)$was prepared via the 1-[3-(dimethylamino)propyl]-3-ethylcarbodiimide methyliodide and ethylenediamine (EDC; Sigma-Aldrich, St Louis, MO, USA)-mediated amine exchange reaction. EDC was added to the prepared $\mathrm{GO}^{-\mathrm{COO}^{-}}$. The solution was stirred rapidly for 12 hours and dialyzed for 4 days in a membrane tube (molecular weight cut off $=12,000-14,000 \mathrm{Da}$ ) to remove any residual chemicals after the reaction.

\section{Multilayer coatings of $\mathrm{Ti}$ substrates with GO}

The concentration of GO in solutions used in all of the GO coating experiments was fixed at $0.05 \%(\mathrm{w} / \mathrm{v})$ without any ionic salts. The $\mathrm{GO}-\mathrm{NH}_{3}{ }^{+} / \mathrm{GO}-\mathrm{COO}^{-}$multilayer coating was administered by first treating Ti substrates with an $\mathrm{O}_{2}$ plasma cleaner (Harrick Scientific Products Inc, Pleasantville, NY, USA) for 5 minutes. GO multilayer films were deposited on the Ti substrates by layer-by-layer (LbL) assembly. ${ }^{34,35}$ Briefly, the substrates were then dipped for 10 minutes in the cationic $\mathrm{GO}-\mathrm{NH}_{3}{ }^{+}$solution, washed three times by dipping in deionized water for 1 minute, and then dried with a gentle stream of nitrogen. The negatively charged $\mathrm{GO}-\mathrm{COO}^{-}$ was subsequently deposited onto the $\mathrm{GO}-\mathrm{NH}_{3}^{+}$coated films using the same adsorption, washing, and drying procedures described above. ${ }^{28} \mathrm{Ti}$ substrates coated with 15 bilayers of $\mathrm{GO}-\mathrm{NH}_{3}^{+} / \mathrm{GO}-\mathrm{COO}^{-}$were used for BMP-2/SP delivery and animal study. The outermost layer of GO coating was GO$\mathrm{COO}^{-}$, which is responsible for effective BMP-2 delivery. ${ }^{28}$

\section{Release kinetics of BMP-2 and SP}

The in vitro release profiles of BMP-2 (Cowell Medi Co, Ltd, Busan, Korea) and SP (Millipore Corporation, Billerica, MA, USA) from Ti- or GO-coated Ti substrate (Ti/GO) for various periods were determined by enzyme-linked immunosorbent assays (ELISA; R\&D Systems Inc, Minneapolis, MN, USA). For loading of BMP-2 and SP on the implants, both BMP-2 $\left(0.16 \mu \mathrm{g} / \mathrm{cm}^{2}\right)$ and $\mathrm{SP}\left(20 \mathrm{ng} / \mathrm{cm}^{2}\right)$ were placed on the implants and lyophilized for 1 day. The BMP-2-loaded and SP-loaded $\mathrm{Ti}$ and $\mathrm{Ti} / \mathrm{GO}$ were immersed in phosphate buffered saline (PBS) at $37^{\circ} \mathrm{C}$. At various time points, the supernatant was collected and the BMP-2 concentration in the supernatant was determined by ELISA ( $\mathrm{n}=5$ per group; R\&D Systems Inc, catalog \#DY355). Briefly, the capture antibody was diluted to the working concentration in PBS without carrier protein, immediately placed on a 96-well microplate (Corning Inc, Corning, NY, USA), and incubated overnight at room temperature. The supernatant was aspirated. Each well was washed with wash buffer and blocked by adding reagent diluents (1\% $[\mathrm{w} / \mathrm{v}]$ of bovine serum albumin in the PBS) to each well. After the washing step of sample or standards added to the plate, detection antibody was added. Then, horseradish-peroxidase conjugated streptavidin was added to each well. Finally, substrate solution was added to each well and the absorbance was read at $450 \mathrm{~nm}$ by a microplate reader (Powerwave; Bio-Tek Instruments Inc, Winooski, VT, USA).

\section{Bioactivity of released BMP-2 in vitro}

The bioactivity of BMP-2 released from Ti or Ti/GO was determined by measuring alkaline phosphatase (ALP) activity of osteoblasts. Calvarial osteoblasts were isolated from the calvaria of neonatal (less than 1-day-old) Sprague Dawley 
rats (Japan SLC, Tokyo, Japan) by a digestive enzymatic process. The bioactivity of the BMP-2 released from the delivery systems in vitro was assessed by determining the ability of BMP-2 to stimulate ALP activity in the cultured rat calvarial osteoblasts. Rat calvarial osteoblasts $\left(3 \times 10^{4}\right.$ cells per well) were plated in the wells of six-well tissue culture plates (Corning Inc). Each delivery vehicle containing BMP-2 $(2 \mu \mathrm{g})$ was placed on a culture insert (Transwell ${ }^{\circledR}$; Corning Inc) in the culture plates. In the daily addition group, $200 \mathrm{ng} / \mathrm{mL}$ of BMP-2 was added to the cell culture medium. The culture medium was Dulbecco's Modified Eagle's Medium (DMEM; Gibco $^{\circledR}$; Life Technologies, Carlsbad, CA, USA) containing $10 \%$ (v/v) fetal bovine serum (FBS; Gibco ${ }^{\circledR}$; Life Technologies) and $1 \%$ penicillin/streptomycin (Gibco ${ }^{\circledR}$; Life Technologies). The medium was changed every 3 days. The ALP activity was determined using p-nitrophenol phosphate (AnaSpec Inc, San Jose, CA, USA) as the substrate. The cultured rat calvarial osteoblasts were rinsed twice with PBS and lysed in alkaline lysis buffer, followed by three freeze-thaw cycles that involved serial exposure to $-70^{\circ} \mathrm{C}$ and $37^{\circ} \mathrm{C}$. The aliquots were incubated in glycine buffer containing $2 \mathrm{mg} / \mathrm{mL}$ of p-nitrophenol phosphate. After 30 minutes, $3 \mathrm{~N} \mathrm{NaOH}$ was added to stop the reaction. The absorbance of $\mathrm{p}$-nitrophenol was measured at $405 \mathrm{~nm}$. The total amount of cellular protein was determined using the Bradford reagent (Sigma-Aldrich). The enzyme activity was then normalized relative to the total amount of cellular protein. The experiments were performed in triplicate. Real-time reverse transcriptase polymerase chain reaction (qRT-PCR) was performed to determine the relative quantity of messenger RNA (mRNA) expression of osteogenic markers, Runx2 (runt-related transcription factor 2) and ALP, in osteoblasts cultured in the presence of BMP-2 released from Ti or Ti/GO. All qRT-PCR reactions were performed using a Light Cycler 480 (F Hoffman-La Roche Ltd, Basel, Switzerland) with SYBR Green I (Takara Bio Inc, Shiga, Japan). After 5 minutes of preincubation at $90^{\circ} \mathrm{C}$, 35 amplification cycles were performed. Each cycle consisted of the following three steps: 30 seconds at $94^{\circ} \mathrm{C}, 45$ seconds at $60^{\circ} \mathrm{C}$, and 45 seconds at $72^{\circ} \mathrm{C}$. The sequences of the primers used for qRT-PCR are shown in Table 1.

\section{In vitro cell migration assay}

To examine the effect of SP on in vitro MSC migration, a collagen gel assay was performed. ${ }^{36}$ Human bone marrowderived MSCs were purchased from Lonza (Walkersville, MD, USA) and cultured on cell culture plates (Corning Inc) with a growth medium that comprised DMEM (Gibco ${ }^{\circledR}$; Life Technologies), 10\% (v/v) fetal bovine serum (Gibco ${ }^{\circledR}$;
Table I Primer sequences used in qRT-PCR analysis to determine the level of gene expression for osteogenic differentiation and BMP-2 bioactivity

\begin{tabular}{ll}
\hline Gene & Primer \\
\hline GAPDH & Sense 5' GTC GGA GTC AAC GGA TTT GG - 3' \\
& Antisense 5' - GGG TGG AAT CAA TTG GAA CAT - 3' \\
Runx2 & Sense 5' - AGA TGA TGA CAC TGC CAC CTC TG - 3' \\
& Antisense 5' - GGG ATG AAA TGC TTG GGA ACT GC - 3' \\
ALP & Sense 5' - CCC TTG ACC CCC ACA ATG T - 3' \\
& Antisense 5' - GTT GTT CCT GTT CAG CTC GTA - 3' \\
\hline
\end{tabular}

Abbreviations: $\mathrm{qRT}-\mathrm{PCR}$, real-time reverse transcriptase polymerase chain reaction; BMP-2, bone morphogenetic protein-2; GAPDH, glyceraldehyde-3phosphate dehydrogenase; Runx2, runt-related transcription factor 2; ALP, alkaline phosphatase.

Life Technologies), and 1\% (v/v) penicillin/streptomycin (Gibco $^{\circledR}$; Life Technologies). The medium was changed every 2 days. After four passages, human bone marrowderived MSCs were used for experiments. For tracking cells in collagen gel, the cytoplasmic membranes of cells were prelabeled with the fluorescent probe cell tracker, 1,1-dioctadecyl-3,3,3',3'-tetramethylindocarbocyanine perchlorate (DiI; Life Technologies). Cells were incubated in the culture medium containing DiI dye $(6.25 \mu \mathrm{g} / \mathrm{mL})$ for 2 hours at room temperature. The labeled cells were washed twice with PBS. Human dermal fibroblast cells were used as a control. Collagen gel was prepared according to Farhat's protocol. ${ }^{37}$ Type I collagen (Sigma-Aldrich) was dissolved in water with acetic acid resulting in a $\mathrm{pH}$ of 3.0. The collagen solution was neutralized with PBS and $\mathrm{NaOH}$ to a $\mathrm{pH}$ of approximately 7.4. The collagen solution was then allowed to form a gel at $37^{\circ} \mathrm{C}$ for an hour at atmospheric humidity. To test the migration of cells under the influence of SP, $5 \times 10^{3}$ DiI-labeled cells were seeded on one end of the collagen gel. SP was loaded on the other end of the gel. The culture medium contained high-glucose DMEM (Gibco ${ }^{\circledR}$; Life Technologies) supplemented with 10\% FBS (Gibco ${ }^{\circledR}$; Life Technologies) and 1\% penicillin/ streptomycin (Gibco ${ }^{\circledR}$; Life Technologies). After 24 hours of culture, the migrated cells that moved through the collagen gel were visualized and photographed using a fluorescence microscope (IX71 inverted microscope; Olympus, Tokyo, Japan). The labeled cells were counted at a high magnification $(\times 40)$. Cells were counted in multiple fields $(n=5$ per group), and the counts were averaged.

\section{Implantation of the Ti or Ti/GO device into mouse calvaria}

Six-week-old mice from the Institute of Cancer Research (Orient Bio Inc, Sungnam, Kyunggi-do, Korea) were anesthetized 
using xylazine $(20 \mathrm{mg} / \mathrm{kg})$ and ketamine $(100 \mathrm{mg} / \mathrm{kg})$. After the scalp hair was shaved, a longitudinal incision was made in the midline of the cranium from the nasal bone to the posterior nuchal line, and the periosteum was elevated to expose the surface of the parietal bones. A $1.2 \mathrm{~mm}$ diameter twist drill was used to make one hole through the calvaria. ${ }^{38}$ Next, a Ti or Ti/GO ring implant (4 $\mathrm{mm}$ in outer diameter, $1.2 \mathrm{~mm}$ in inner diameter) with or without SP and/or BMP-2 loading was placed beneath the periosteum, directly on the hole of the occipital bone. The implant was stabilized using a screw ( $2 \mathrm{~mm}$ in diameter). The drilling site was irrigated with saline, and the bleeding points were electrocauterized. Each animal had one implant, and five animals were used for each group. The animals were divided into eight groups: pristine Ti (Ti), GO-coated Ti (Ti/GO), SP-loaded Ti (Ti/SP), BMP-2-loaded Ti (Ti/BMP-2), SP-loaded Ti/GO (Ti/GO/ SP), BMP-2-loaded Ti/GO (Ti/GO/BMP-2), SP and BMP-2loaded Ti (Ti/SP/BMP-2), and SP and BMP-2-loaded Ti/GO (Ti/GO/SP/BMP-2). The amount of SP loaded in the animal groups with or without GO-coated Ti plates was $0.2 \mu \mathrm{g}$, and the amount of BMP-2 loaded on each delivery system was $2 \mu \mathrm{g}$. The animal study was approved by the Institutional Animal Care and Use Committee of Seoul National University (SNU-120711-4).

\section{Histology}

Eight weeks after implantation, all animals were sacrificed and the samples were retrieved. The specimens were prepared for histological and histomorphometric analysis $(n=5)$. The specimens were immersed in $10 \%(\mathrm{v} / \mathrm{v})$ buffered formalin solution, dehydrated in alcohol solutions of increasing concentrations, clarified in xylene, and embedded in polymethylmethacrylate. One sagittal and one frontal section (10 $\mu \mathrm{m}$ in thickness) from each of two specimens per animal were obtained using a microcutting and grinding technique. The sections were stained with Goldner's trichrome stain. The area of bone formation was determined using Adobe Photoshop software (Adobe Systems Inc, San Jose, CA, USA) based on the percentage of newly formed mineralized bone, excluding marrow and fibrovascular tissue in the original bone defect area (new bone area/defect area $\times 100, n=5$ per group).

\section{Statistical analysis}

Quantitative data were expressed as the mean \pm standard deviation. Statistical analysis was performed using oneway analysis of variance with the Tukey significant difference post-hoc test using SPSS software (IBM Corporation,
Armonk, NY, USA). A value of $P<0.05$ was considered to denote statistical significance.

\section{Results \\ Coating of Ti substrates with GO}

To ensure full coverage of Ti substrates with GO sheets (single GO sheet area $=0.75 \pm 0.12 \mu \mathrm{m}^{2}$, Figure $1 \mathrm{~A}$ ), the Ti substrate was alternatively coated with positively and negatively charged $\mathrm{GO}$ sheets $\left[\mathrm{GO}-\mathrm{NH}_{3}{ }^{+}\right.$and $\mathrm{GO}-\mathrm{COO}^{-}$, respectively] using LbL assembly. ${ }^{29,34,35}$ Coating with multiple layers of GO resulted in a full coverage of the Ti substrate (Figure 1A). Atomic force microscopy revealed that, unlike the bumpy surface of an uncoated Ti substrate, the GOcoated Ti surfaces became much smoother after multiple cycles of LbL deposition. Full coverage of the GO sheets on Ti substrates was realized by LbL assembly of 15 bilayers. The GO coating on Ti was also confirmed by X-ray photoelectron spectroscopy (Figure 1B). The C(1s) peak, which normally originates from GO, is clearly evident at approximately $285 \mathrm{eV}$ in the spectrum of the GO-coated Ti. The increased number of GO bilayers caused the increased $\mathrm{C}(1 \mathrm{~s})$ peak, whereas the characteristic peaks of $\operatorname{Ti}\left(2 \mathrm{p}_{3 / 2}\right)$ at $459 \mathrm{eV}$ and $\mathrm{Ti}\left(2 \mathrm{p}_{1 / 2}\right)$ at $463 \mathrm{eV}$ are almost absent after coating Ti with GO sheets. Coating with GO eliminated the relatively hydrophobic nature of $\mathrm{Ti}$, and $\mathrm{Ti} / \mathrm{GO}$ with 15 bilayers was more hydrophilic than unmodified $\mathrm{Ti}$, owing to the polar modification with the GO sheets (Figure 1C). GO coating on Ti surface changed the color of Ti to black, which was originated from GO (Figure 1D).

\section{Sustained release of BMP-2 and SP from $\mathrm{Ti}$ or $\mathrm{Ti} / \mathrm{GO}$ substrates}

The in vitro release of BMP-2 from the Ti/GO substrate was maintained for 14 days (Figure 2). In contrast, Ti exhibited an initial burst of BMP-2 release. More than $72 \%$ of the initially loaded BMP-2 was released from Ti within a day. Less than $50 \%$ of BMP-2 was released from the Ti/GO within a day. The in vitro release of SP was also measured by ELISA (Figure $3 \mathrm{~A}$ ). Less than $80 \%$ of SP was gradually released in 14 days. There was no significant difference in SP release between Ti and Ti/GO.

\section{Bioactivity of released BMP-2}

We compared the bioactivities of BMP-2 released from bare $\mathrm{Ti}$ and $\mathrm{Ti} / \mathrm{GO}$ (Figure 2B). Bioactive BMP-2 released from both carriers increased the ALP activity of cultured osteoblasts. The ALP activity of osteoblasts was significantly higher in the $\mathrm{Ti} / \mathrm{GO} / \mathrm{BMP}-2$ group compared with the 


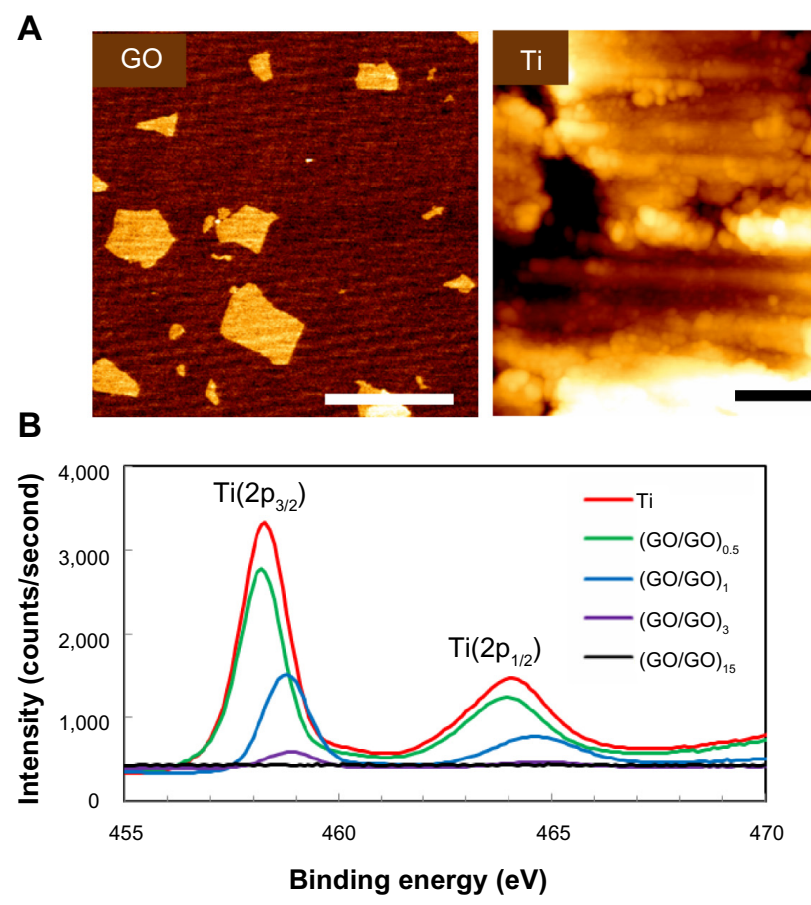

C

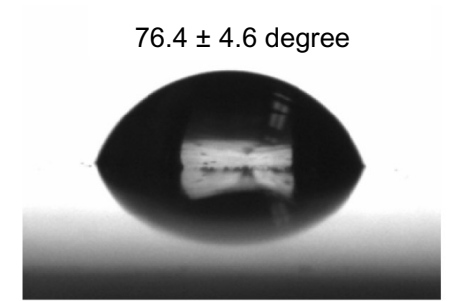

$\mathrm{Ti}$

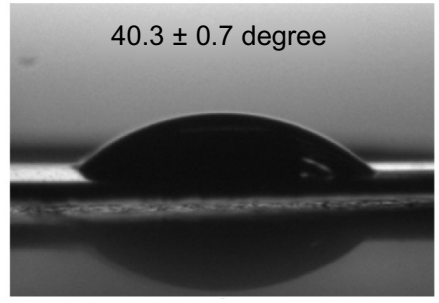

$\mathrm{Ti} / \mathrm{GO}$

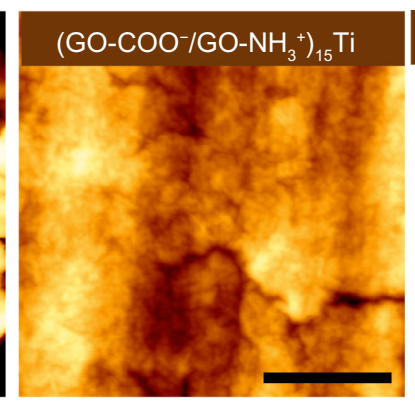

Roughness

$100 \mathrm{~nm}$
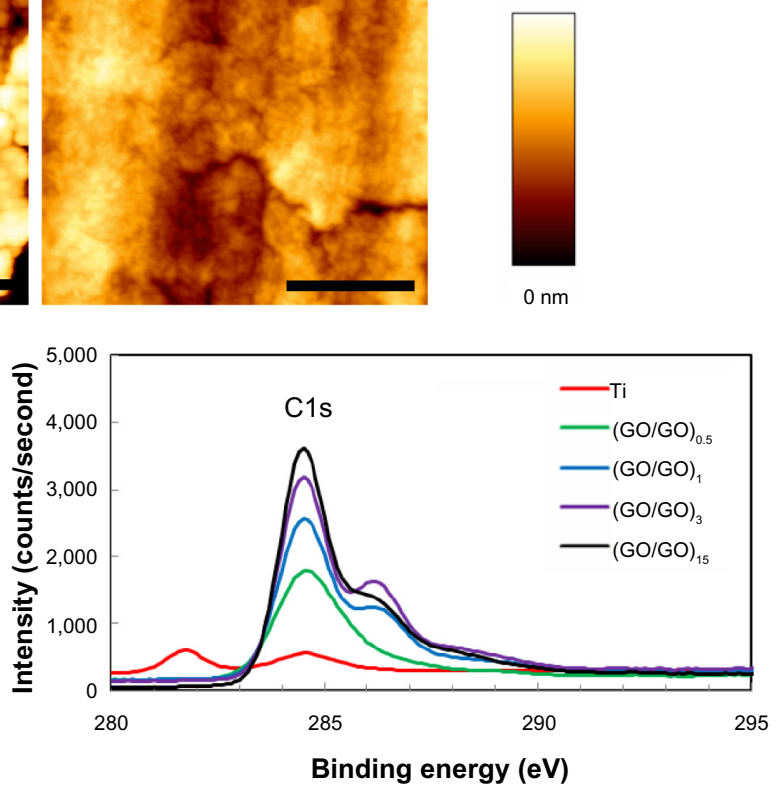

D

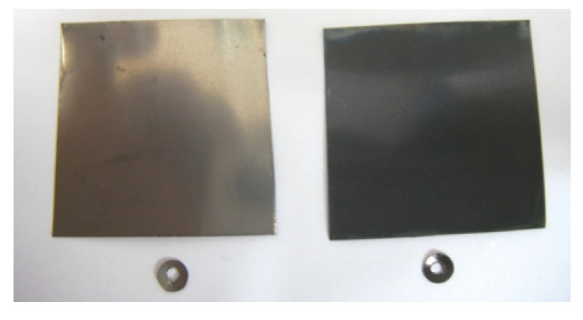

$\mathrm{Ti}$

Figure I Coating of graphene oxide multilayers onto titanium substrates.

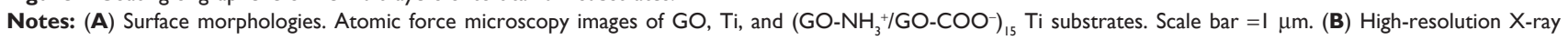
photoelectron spectra of (GO-NH$\left.{ }_{3}^{+} / \mathrm{GO}-\mathrm{COO}^{-}\right) \mathrm{nTi}$ substrates. $(\mathbf{C})$ Contact water angles of bare $\mathrm{Ti}$ and $\mathrm{Ti} / \mathrm{GO}$, showing the change of the relatively hydrophobic nature of $\mathrm{Ti}$ to the more hydrophilic nature of GO. (D) Optical images of $\mathrm{Ti}$ and $\mathrm{Ti} / \mathrm{GO}$.

Abbreviations: $\mathrm{GO}$, graphene oxide; $\mathrm{Ti}$, titanium.

Ti/BMP-2 group for 14 days of incubation and was similar to the group with daily addition of BMP-2 to the culture medium (positive control). The mRNA expressions of cultured osteoblasts were evaluated by qRT-PCR (Figure 2C). Runx2 expression was significantly higher in the BMP-2 groups, but there was no significant difference between the groups. mRNA expression of an early osteogenic differentiation marker, ALP, was significantly increased in Ti/GO/BMP-2 compared to Ti/BMP-2.

\section{SP stimulated MSCs migration in vitro}

The potential of SP for inducing migration of MSCs was evaluated. The test scheme is depicted in Figure 3B. SP stimulated MSC migration in collagen gel. In contrast, human dermal fibroblast cell migration was negligible for 24 hours in the presence of SP.

\section{Enhanced in vivo bone formation by dual delivery of BMP-2 and SP using Ti/GO substrate in mouse}

The therapeutic efficacy of BMP-2 and SP delivered by Ti or Ti/GO substrate was investigated in vivo by evaluating bone formation after implantation of $\mathrm{Ti}$ or $\mathrm{Ti} / \mathrm{GO}$ substrate with or without BMP-2 and/or SP into the mouse calvaria (Figure 4). All animals survived for the entire implantation period ( 8 weeks). Histological analysis with Goldner's trichrome staining revealed BMP-2/SP and the carrierdependent formation of new bone (Figure 4). Negligible bone formation on $\mathrm{Ti}$ and $\mathrm{Ti} / \mathrm{GO}$ implants was observed in the groups without BMP-2 (Ti, Ti/SP, Ti/GO and Ti/GO/ $\mathrm{SP})$. The GO-coated implants with BMP-2 showed much extensive bone formation compared with bare Ti implants with BMP-2. There was no significant difference between 
A

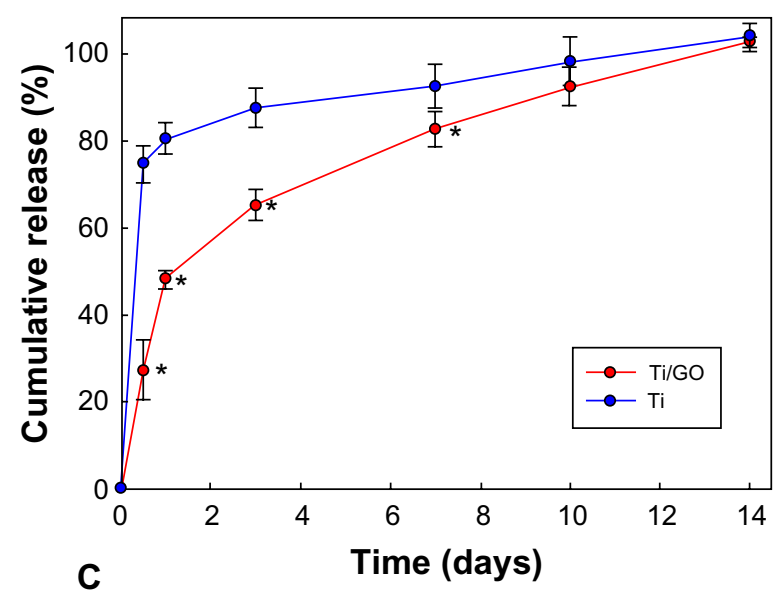

C

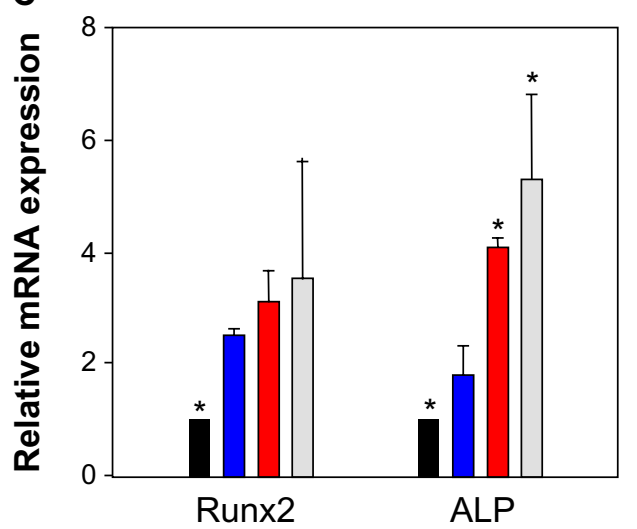

B

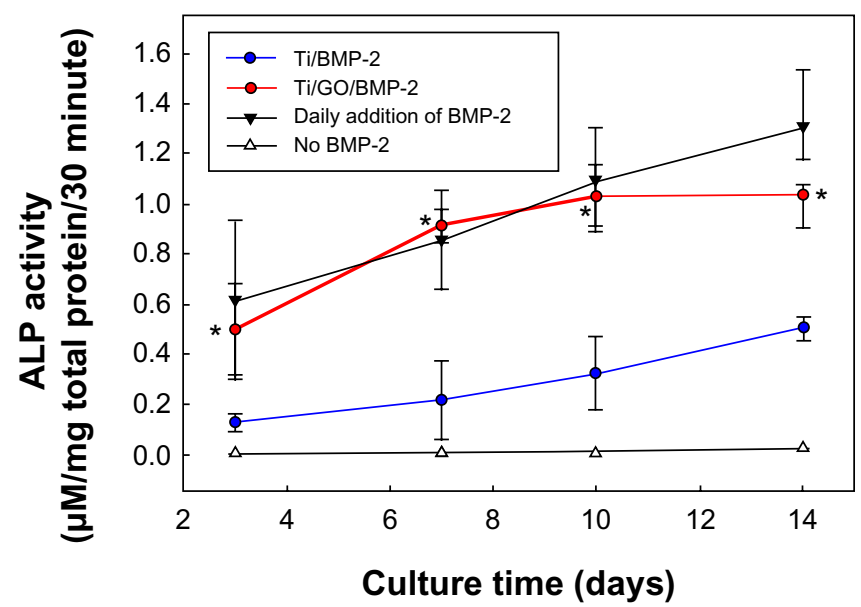

Figure 2 Bone morphogenetic protein-2 delivery.

Notes: (A) Kinetics of in vitro release of BMP-2 from Ti and Ti/GO substrates. The BMP-2 loaded Ti and Ti/GO were immersed in phosphate-buffered saline at $37^{\circ} \mathrm{C}$. At various time points, the supernatant was collected and the concentration of BMP- 2 in the supernatant was determined by enzyme-linked immunosorbent assay ( $\mathrm{n}=5$ per group). $* P<0.05$ compared with Ti. (B) Bioactivity of BMP-2 released from Ti and Ti/GO substrates, as evaluated by measuring the ALP activity. (C) Bioactivity of BMP-2 released from $\mathrm{Ti}$ and $\mathrm{Ti} / \mathrm{GO}$ substrates, as evaluated by measuring mRNA expression of osteogenic markers, Run 2 and ALP, of osteoblasts cultured on a tissue culture plate with or without the BMP-2 delivery device. Cultures with or without a daily addition of BMP-2 to the culture medium served as controls. $* P<0.05$ compared with Ti/BMP-2.

Abbreviations: Ti, titanium; GO, graphene oxide; ALP, alkaline phosphatase; BMP-2, bone morphogenetic protein-2; mRNA, messenger ribonucleic acid; Runx2, runtrelated transcription factor 2 .

Ti/BMP-2 and Ti/SP/BMP-2. However, Ti/GO/SP/BMP-2 implants showed much more extensive bone formation than Ti/GO/BMP-2 implants.

\section{Discussion}

In this study, the in situ tissue regeneration approach was used to regenerate bone tissue. This method has many advantages over stem cell transplantation therapy, which generally requires ex vivo cell manipulation. The stem cell culture for cell expansion and differentiation increases the treatment cost and can take more than 3-4 weeks, during which patients have to wait. The in situ tissue regeneration approach avoids stem cell transplantation and could overcome the obstacles of stem cell therapy. The in situ tissue regeneration involves the recruitment of endogenous stem cells or progenitor cells to the site for tissue regeneration and subsequent differentiation of the recruited cells into tissue-specific cell types. ${ }^{39,40}$ In this study, we used SP, which is known to recruit MSCs from bone marrow to the blood circulation, ${ }^{41}$ as a chemotaxis agent. SP released from GO coated on Ti implants may recruit MSCs to the Ti implants. The in vitro migration data (Figure 3) showed that SP stimulated MSC migration. To induce osteogenic differentiation of the recruited stem cells or progenitor cells and subsequent bone formation, BMP-2 was also delivered using GO.

GO enabled sustained release of BMP-2 and high bioactivity of the released BMP-2 (Figure 2), both of which are important for effective bone formation. BMP-2 must be released for a long period to ensure osteogenic differentiation of stem cells or progenitor cells because the differentiation process takes several weeks. ${ }^{8-11}$ Our previous study also showed that GO can allow for sustained release of BMP-2.28 $\mathrm{GO}^{-\mathrm{COO}^{-}}$has hydrophobic $\pi$ domains mainly located on the basal plane and ionized carboxylic acids at their edges. 


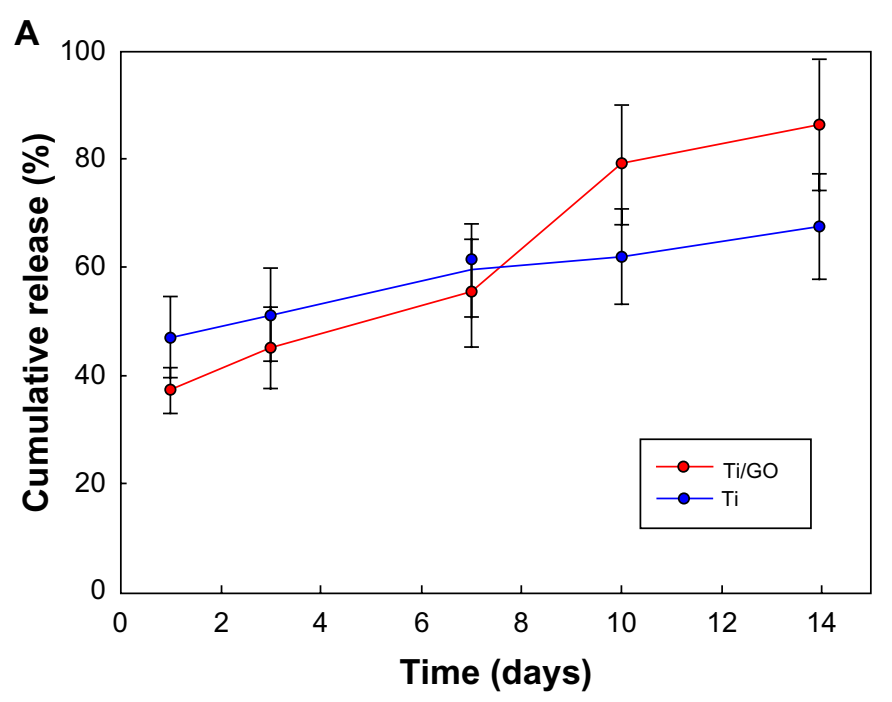

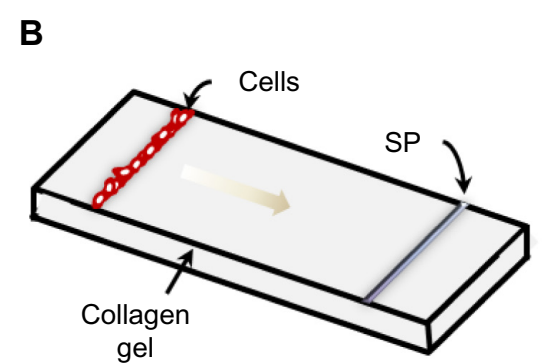

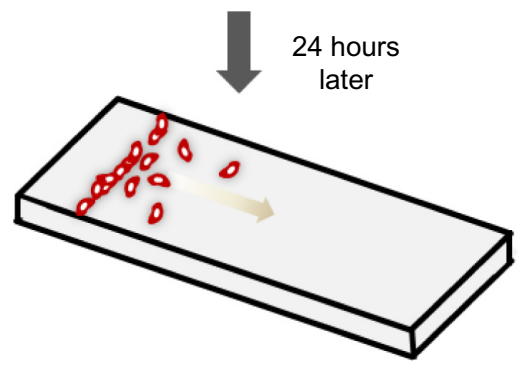

C

$\mathrm{Oh}$

$24 \mathrm{~h}$
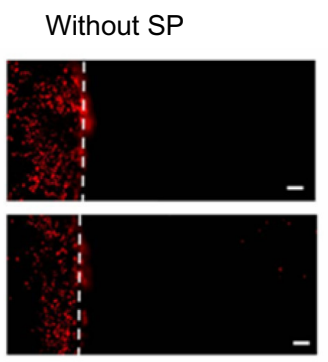

$\mathrm{Oh}$

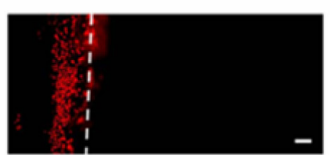

$24 \mathrm{~h}$
With SP

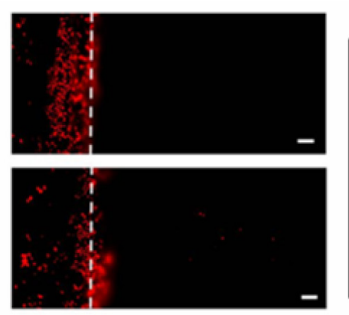

Fibroblasts
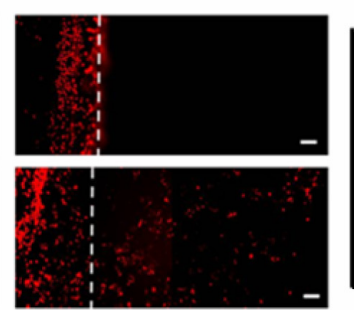

MSCs

Figure 3 Substance $P$ delivery.

Notes: (A) Kinetics of in vitro release of SP from Ti and Ti/GO substrates. No statistical significance was found between the two groups at all time points. (B-C) In vitro migration of MSCs stimulated by SP. (B) Schematic diagram of cell migration in collagen gel entrapped between two slide glasses. Dil-labeled fibroblasts or MSCs were seeded on one end of the collagen gel, and SP was loaded on the other end of the gel. (C) Fluorescence images of the location of Dil-labeled cells inside the gel a day after seeding and SP release. Scale bar $=200 \mu \mathrm{m}$.

Abbreviations: SP, substance P; Ti, titanium; GO, graphene oxide; MSC, mesenchymal stem cell; Dil, I,I-dioctadecyl-3,3,3',3'-tetramethylindocarbocyanine perchlorate.

$\pi$-electron clouds in GO are capable of interacting with the inner hydrophobic cores of BMP-2 protein. In addition, the negatively charged $\mathrm{COO}^{-}$domains of $\mathrm{GO}^{-\mathrm{COO}^{-}}$can also bind with positively charged BMP-2 through electrostatic interactions. ${ }^{31.33}$ These interactions are thought to be responsible for the sustained release of BMP-2 from GO. In contrast, the release kinetics of SP from Ti and Ti/GO were not different (Figure 3A), probably because SP does not have a considerable extent of hydrophobic $\pi-\pi$ interaction with GO. Our previous study also showed that BMP-2 adsorbed on GO was protected from protein denaturation through electrostatic interactions with the hydrophilic terminal functional groups attached to the GO. ${ }^{28}$ The high bioactivity of BMP-2 was confirmed by high ALP activity of cultured osteoblasts (Figure 2B). The features of sustained release of BMP-2 and high bioactivity of the released BMP-2, which are enabled by $\mathrm{GO}$, allowed for extensive bone formation on GO-coated Ti implants (Figure 4).

Dual delivery of BMP-2 and SP further enhanced in vivo bone formation compared with delivery of BMP-2 only (Figure 4). Our previous study showed that BMP-2 delivery using $\mathrm{GO}$ enhanced in vivo bone formation. ${ }^{28}$ The greater bone formation in the Ti/GO/SP/BMP-2 group compared with the Ti/GO/BMP-2 group may be due to the MSC recruitment by 


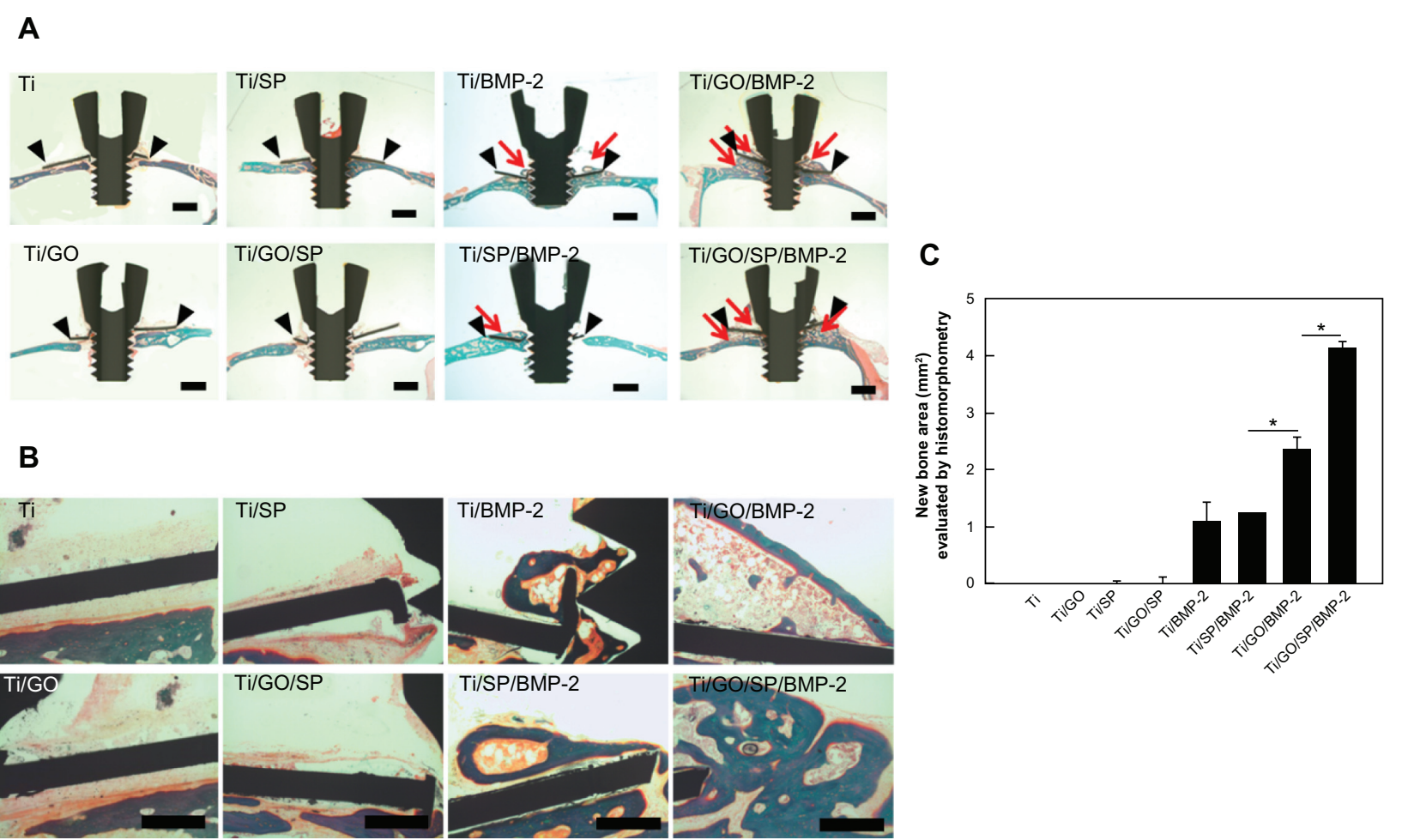

Figure 4 Bone regeneration of Ti ring implants with or without GO coating and BMP-2/SP loading in mouse calvarial defect model.

Notes: Histological analysis with Goldner's trichrome staining of mouse calvarial defects with implants 8 weeks after treatment. (A) Lower magnification $(\times 12.5)$ images of the implants. The black arrowheads and red arrows indicate the implant and newly formed bone, respectively. Scale bars $=1 \mathrm{~mm}$. (B) Higher magnification $(\times 100)$ images of the implants. Scale bars $=100 \mu \mathrm{m}$. (C) The area of new bone formation was determined using histomorphometric analysis ( $\mathrm{n}=5$ ). $* P<0.05$ between designated two groups. Abbreviations: $\mathrm{Ti}$, titanium; GO, graphene oxide; BMP-2, bone morphogenetic protein-2; SP, substance P.

SP to the implants. However, the Ti/SP/BMP-2 group did not show improved bone formation compared with Ti/BMP-2. In addition, Ti/SP/BMP-2 and Ti/GO/SP showed significantly less bone formation than Ti/GO/BMP-2. This result indicated that sustained delivery of BMP-2 is more essential than stem cell recruitment by SP for bone formation. Unlike BMP-2, SP does not require sustained delivery. The existence of SP in the blood is sufficient for stem cell recruitment. Therefore, our GO/SP delivery platform did not show significant differences in SP delivery kinetics compared with the bare Ti platform. In addition to the delivery of BMP-2 and SP using GO, enhanced adhesion of recruited cells on GO might be partially responsible for the enhanced bone formation. ${ }^{30}$

The proposed method could be useful to improve osteointegration of dental or orthopedic implants. Although Ti implants have widely been used as biomedical materials in orthopedic surgery and dentistry, a lack of integration with bone tissue at the implantation site is the critical limitation of these implants. ${ }^{22} \mathrm{Ti}$ implants have been coated with hydroxyapatite to improve osteointegration. ${ }^{22-25}$ However, effective bone formation was not observed at the space between the implants and implantation site, which could be because hydroxyapatite is osteoconductive but not osteoinductive.
The use of BMP-2 might improve the osteointegration of implants by stimulating bone formation. ${ }^{22-25}$ However, an appropriate carrier for BMP-2 delivery is necessary for effective bone formation. This study showed that GO is an appropriate carrier for BMP-2 delivery and that Ti implants modified with GO could be a solution for the improvement in osteointegration of dental or orthopedic implants.

\section{Conclusion}

In this study, we used a GO-coated Ti substrate as a vehicle for delivery of BMP-2, an osteoinductive, and SP, a stem cell recruitment agent for in situ bone regeneration. GO was able to release BMP-2 in a sustained manner. The delivery of BMP-2 and SP using GO enhanced the bone formation on Ti implanted in the mouse calvaria. The dual delivery of BMP-2 and SP could be used to improve osteointegration of dental or orthopedic implants.

\section{Acknowledgments}

This study was supported by the Korea Health 21 R\&D Project, Ministry of Health and Welfare (A100443), and the National Research Foundation of Korea (NRF) grant funded by the Korean government (MSIP) (No 2010-0018290). 


\section{Disclosure}

The authors report no conflicts of interest in this work.

\section{References}

1. Reddi AH. BMPs: from bone morphogenetic proteins to body morphogenetic proteins. Cytokine Growth Factor Rev. 2005;16(3):249-250.

2. Bessa PC, Casal M, Reis RL. Bone morphogenetic proteins in tissue engineering: the road from laboratory to clinic, part II (BMP delivery). J Tissue Eng Regen Med. 2008;2(2-3):81-96.

3. Gautschi OP, Frey SP, Zellweger R. Bone morphogenetic proteins in clinical applications. ANZ J Surg. 2007;77(8):626-631.

4. Termaat MF, Den Boer FC, Bakker FC, Patka P, Haarman HJ. Bone morphogenetic proteins. Development and clinical efficacy in the treatment of fractures and bone defects. J Bone Joint Surg Am. 2005;87(6):1367-1378.

5. Govender S, Csimma C, Genant HK, et al; BMP-2 Evaluation in Surgery for Tibial Trauma (BESTT) Study Group. Recombinant human bone morphogenetic protein-2 for treatment of open tibial fractures: a prospective, controlled, randomized study of four hundred and fifty patients. J Bone Joint Surg Am. 2002;84-A(12):2123-2134.

6. Haidar ZS, Hamdy RC, Tabrizian M. Delivery of recombinant bone morphogenetic proteins for bone regeneration and repair. Part A: Current challenges in BMP delivery. Biotechnol Lett. 2009;31(12): 1817-1824.

7. Poynton AR, Lane JM. Safety profile for the clinical use of bone morphogenetic proteins in the spine. Spine. 2002;27(16 Suppl 1):S40-S48.

8. Shields LB, Raque GH, Glassman SD, et al. Adverse effects associated with high-dose recombinant human bone morphogenetic protein-2 use in anterior cervical spine fusion. Spine. 2006;31(5):542-547.

9. Bessa PC, Casal M, Reis RL. Bone morphogenetic proteins in tissue engineering: the road from laboratory to clinic, part II (BMP delivery). J Tissue Eng Regen Med. 2008;2(2-3):81-96.

10. Takahashi Y, Yamamoto M, Tabata Y. Enhanced osteoinduction by controlled release of bone morphogenetic protein-2 from biodegradable sponge composed of gelatin and beta-tricalcium phosphate. Biomaterials. 2005;26(23):4856-4865.

11. Yang HS, La WG, Bhang SH, Jeon JY, Lee JH, Kim BS. Heparinconjugated fibrin as an injectable system for sustained delivery of bone morphogenetic protein-2. Tissue Eng Part A. 2010;16(4):1225-1233.

12. Otsuru S, Tamai K, Yamazaki T, Yoshikawa H, Kaneda Y. Circulating bone marrow-derived osteoblast progenitor cells are recruited to the bone-forming site by the CXCR4/stromal cell-derived factor-1 pathway. Stem Cells. 2008;26(1):223-234.

13. Ko IK, Ju YM, Chen T, Atala A, Yoo JJ, Lee SJ. Combined systemic and local delivery of stem cell inducing/recruiting factors for in situ tissue regeneration. FASEB J. 2012;26(1):158-168.

14. Hylden JL, Wilcox GL. Intrathecal substance P elicits a caudally-directed biting and scratching behavior in mice. Brain Res. 1981;217(1): 212-215.

15. O'Connor TM, O'Connell J, O'Brien DI, Goode T, Bredin CP, Shanahan F. The role of substance $\mathrm{P}$ in inflammatory disease. J Cell Physiol. 2004;201(2):167-180.

16. Bowden JJ, Garland AM, Baluk P, et al. Direct observation of substance P-induced internalization of neurokinin $1(\mathrm{NK} 1)$ receptors at sites of inflammation. Proc Natl Acad Sci U S A. 1994;91(19):8964-8968.

17. Nakamura M, Kawahara M, Morishige N, Chikama T, Nakata K, Nishida T. Promotion of corneal epithelial wound healing in diabetic rats by the combination of a substance P-derived peptide (FGLM-NH2) and insulin-like growth factor-1. Diabetologia. 2003;46(6):839-842.

18. Kohara H, Tajima S, Yamamoto M, Tabata Y. Angiogenesis induced by controlled release of neuropeptide substance P. Biomaterials. 2010;31(33):8617-8625.

19. Ziche M, Morbidelli L, Pacini M, Geppetti P, Alessandri G, Maggi CA. Substance P stimulates neovascularization in vivo and proliferation of cultured endothelial cells. Microvasc Res. 1990;40(2):264-278.

20. Hong HS, Lee J, Lee E, et al. A new role of substance $P$ as an injuryinducible messenger for mobilization of CD29(+) stromal-like cells. Nat Med. 2009;15(4):425-435.
21. Carlsson O, Schizas N, Li J, Ackermann PW. Substance P injections enhance tissue proliferation and regulate sensory nerve ingrowth in rat tendon repair. Scand J Med Sci Sports. 2011;21(4): $562-569$.

22. Lucas LC, Lacefield WR, Ong JL, Whitehead RY. Calcium phosphate coatings for medical and dental implants. Colloids Surf A Physicochem Eng Asp. 1993;77(2):141-147.

23. Thomas KA, Kay JF, Cook SD, Jarcho M. The effect of surface macrotexture and hydroxylapatite coating on the mechanical strengths and histologic profiles of titanium implant materials. J Biomed Mater Res. 1987;21(12):1395-1414.

24. Maxian SH, Zawadsky JP, Dunn MG. In vitro evaluation of amorphous calcium phosphate and poorly crystallized hydroxyapatite coatings on titanium implants. J Biomed Mater Res. 1993;27(1):111-117.

25. Le Guéhennec L, Soueidan A, Layrolle P, Amouriq Y. Surface treatments of titanium dental implants for rapid osseointegration. Dent Mater. 2007;23(7):844-854.

26. Kim SE, Song SH, Yun YP, et al. The effect of immobilization of heparin and bone morphogenic protein-2 (BMP-2) to titanium surfaces on inflammation and osteoblast function. Biomaterials. 2011;32(2): 366-373.

27. Bae SE, Choi J, Joung YK, Park K, Han DK. Controlled release of bone morphogenetic protein (BMP)-2 from nanocomplex incorporated on hydroxyapatite-formed titanium surface. $J$ Control Release. 2012;160(3):676-684.

28. La WG, Park S, Yoon HH, et al. Delivery of a therapeutic protein for bone regeneration from a substrate coated with graphene oxide. Small. Epub July 10, 2013.

29. Hong J, Shah NJ, Drake AC, et al. Graphene multilayers as gates for multi-week sequential release of proteins from surfaces. ACS Nano. 2012;6(1):81-88.

30. Ruiz ON, Fernando KA, Wang B, et al. Graphene oxide: a nonspecific enhancer of cellular growth. ACS Nano. 2011;5(10):8100-8107.

31. Weber D, Kotzsch A, Nickel J, et al. A silent H-bond can be mutationally activated for high-affinity interaction of BMP-2 and activin type IIB receptor. BMC Struct Biol. 2007;7:6.

32. Mücksc C, Urbassek HM. Adsorption of BMP-2 on a hydrophobic graphite surface: a molecular dynamics study. Chem Phys Lett. 2011;510(4-6):252-256.

33. Utesch T, Daminelli G, Mroginski MA. Molecular dynamics simulations of the adsorption of bone morphogenetic protein- 2 on surfaces with medical relevance. Langmuir. 2011;27(21):13144-13153.

34. Park S, Bhang SH, La WG, Seo J, Kim BS, Char K. Dual roles of hyaluronic acids in multilayer films capturing nanocarriers for drugeluting coatings. Biomaterials. 2012;33(21):5468-5477.

35. Jang Y, Park S, Char K. Functionalization of polymer multilayer thin films for novel biomedical applications. Korean J Chem Eng. 2011;28(5):1149-1160.

36. Hur J, Yang HM, Yoon CH, et al. Identification of a novel role of T cells in postnatal vasculogenesis: characterization of endothelial progenitor cell colonies. Circulation. 2007;116(15):1671-1682.

37. Farhat YM, Al-Maliki AA, Chen T, et al. Gene expression analysis of the pleiotropic effects of TGF- $\beta 1$ in an in vitro model of flexor tendon healing. PLoS ONE. 2012;7(12):e51411.

38. Freilich M, Patel CM, Wei M, et al. Growth of new bone guided by implants in a murine calvarial model. Bone. 2008;43(4): 781-788.

39. Shahdadfar A, Frønsdal K, Haug T, Reinholt FP, Brinchmann JE. In vitro expansion of human mesenchymal stem cells: choice of serum is a determinant of cell proliferation, differentiation, gene expression, and transcriptome stability. Stem Cells. 2005;23(9):1357-1366.

40. Hildebrandt $C$, Büth $H$, Thielecke $H$. Influence of cell culture media conditions on the osteogenic differentiation of cord blood-derived mesenchymal stem cells. Ann Anat. 2009;191(1):23-32.

41. Hong HS, Kim do Y, Yoon KJ, Son Y. A new paradigm for stem cell therapy: substance-P as a stem cell-stimulating agent. Arch Pharm Res. 2011;34(12):2003-2006. 


\section{Publish your work in this journal}

The International Journal of Nanomedicine is an international, peerreviewed journal focusing on the application of nanotechnology in diagnostics, therapeutics, and drug delivery systems throughout the biomedical field. This journal is indexed on PubMed Central, MedLine, CAS, SciSearch $\AA$, Current Contents ${ }^{\circledR} /$ Clinical Medicine,

Journal Citation Reports/Science Edition, EMBase, Scopus and the Elsevier Bibliographic databases. The manuscript management system is completely online and includes a very quick and fair peer-review system, which is all easy to use. Visit http://www.dovepress.com/ testimonials.php to read real quotes from published authors.

Submit your manuscript here: http://www.dovepress.com/international-journal-of-nanomedicine-journal 